\title{
The Impact of Adaptive Media Technology on the Achievement of Students with Learning Disabilities in English Language
}

\author{
Mohammad Abedrabbu Alkhawaldeh *, Mohamad Ahmad Saleem Khasawneh ${ }^{* *}$ \\ * Special Education Department, King Khalid University \\ ** Special Education Department, King Khalid University \\ DOI: 10.29322/IJSRP.11.11.2021.p11948 \\ http://dx.doi.org/10.29322/IJSRP.11.11.2021.p11948
}

\begin{abstract}
The aim of the current research is to explore the impact of adaptive media technology on the achievement among students with learning disabilities in English language. Therefore, learning content was designed and developed adaptively according to adaptive media technology via the Internet. From (38) learning disabilities students of the elementary level in Abha schools, the results showed a clear impact of adaptive media technology on the development of achievement or students' performance. In light of this, we conclude that adaptive media technology plays an important role in improving students' learning in the education stage.
\end{abstract}

Keywords: Adaptive Media Technology, Achievement of Students, Learning Disabilities, English Language

\section{INTRODUCTION}

$\mathrm{T}$ oday we live in an era characterized by rapid and tremendous development in various aspects of life (Anindyaputri, Yuana \& Hatta, 2020). Where humanity has witnessed rapid and growing progress in the development of knowledge, and the acceleration of information, educational terms have appeared indicating the penetration of technology into human life; Because of the great invention of computer technology and the Internet, those interested in education began to benefit from the capabilities of the computer; by including it in the educational process, and soon the voices of educators called out and searched for the best means of communication to transfer information and exchange opinions and experiences (Khasawneh, 2021). The interest in customizing and adapting the learning environment has become necessary in order to provide flexible learning that suits all students and takes into account the individual differences between them (Paredes \& Hsiao, 2021). This interest has increased with the emergence of new e-learning strategies and environments, where a single style of learning environment does not suit all categories of students due to their different needs and learning styles (Oira, 2016). Adaptive e-learning has various systems and technologies, including media technology, defined as Adaptive Hypermedia Systems (AHSs), that offer users a lot of freedom across hyperspaces over the Internet, and integrate hypermedia with the user model (Phobun \& Vicheanpanya, 2010). (Oira, 2016) argue that adaptive media technology is specifically designed to overcome the "one size fits all" argument as it provides a rich framework that meets the needs of online learners, and through the user model provides structures of links Within the e-learning environment, it allows the learner to go to the information that interests him. Perelmutter, McGregor and Gordon (2017) indicated that adaptive multimedia systems via the Internet include new features that allow the learner to choose and guide, and they are open systems that allow the use of other sources on the web and aim to adapt the presentation of educational content on the basis of the learner's goals and knowledge, in addition to adapting the process of sailing by selecting the appropriate paths for the learner.

There are many previous studies that were conducted with the aim of arriving at best practices for designing adaptive media systems, some of which focused on studying adaptive navigation techniques, and others are based on adaptive presentation techniques (Elmabaredy, Elkholy \& Tolba, 2020). Multimedia is one of the technological innovations that have appeared in the field of education, as it puts the learner in an educational 
climate in which multiple educational means are available in an integrated form from multiple sources to form a single systemic format that helps the learner to achieve clear goals previously identified and expected to be achieved with a high degree of efficiency as a result of interaction between the learner and the multimedia that affects the increase in learning skills and thus improves their academic achievement in general for learners (Viner, Singh \& Shaughnessy, 2020).

It is possible to benefit from education using multimedia as one of the methods of self-education and function in the educational process (Careen, 2016). The teaching model designed from programs based on multimedia is a technical model that is affected by the multimedia properties of images, text, video and sound, which makes self-learning easier and more effective and improves the academic achievement of students In general, and students with learning disabilities in particular (Khasawneh, 2022). Some may think that the use of educational programs may reduce the role of the teacher in the classroom, but the opposite is true (Erdem, 2017). The importance of the teacher has increased in the presence of the computer, as he is the person who helps the other to learn, not the one who teaches them (Polat et al ., 2012).

Adaptive media technology is defined as systems that provide users with a lot of freedom across vast online spaces, and integrate hypermedia with the user model, the content provided by the system corresponds to the user's knowledge, goals, and preferences (Erdem, 2017). Adaptation in adaptive media systems, in general, includes two areas: adaptive presentation and adaptive navigation. Each field has different techniques (polat et al., 2012). For example, the adaptive presentation includes techniques such as multimedia, conditional text, various pages, various sections, and frames. Adaptive navigation such as comments, hide links, show links, direct guiding, and maps (Standen et al., 2020).

\section{The Role of Educational Technology in HelPing Students with Learning DisabilitiES}

Adaptive media technology is one of the educational technology products, and it is not educational devices, as these devices are only tools in the hands of educational technology (Standen et al., 2020). Educational technology products (educational aids) play a major role in the teaching and learning processes, as they help the teacher to explain the information and also help the learner to absorb the information, we can summarize this importance in the following points:

1) Arousing the learner's interest in topics: the learner should be motivated to learn, then he can be used teaching aids that illustrate this task as a movie or an image or to display examples illustrate the benefits of subject to learners and their attitude towards what needs to be learned and the more educational experiences that provide learners with special needs closer with realism has become a concrete meaning and closely related to the goals that striving to achieve it (Alghayth, 2019).

2) Overcoming the verbal problem: Some educational situations may include presenting the student with some scientific concepts in terms or words that are difficult for the student with visual, hearing or mental disabilities to understand. But by using the appropriate means to clarify or simplify this concept in a material way (Alghayth, 2019).

3) Expanding and diversifying the fields of experience: using educational means provides the learner with the opportunity to watch, listen, practice, reflect and think, thus enriching the areas of expertise that the learner passes through. Thus, all of the student's (healthy) senses participate in the learning processes (Alghayth, 2019).

4) Creating direct educational experiences: Some subjects are related to external environments, which may be difficult for individuals with disabilities to fully understand as a result of what is imposed by the 
deficiency resulting from a lack of one of the senses. Educational media play a role in creating opportunities for students to gain direct experiences through the various activities that permeate the teaching of these subjects, whether on trips and field visits ((Alghayth, 2019).

5) Providing the opportunity for people with disabilities to learn through alternative experiences: There are situations and circumstances that make it impossible or difficult for a person to learn from real and realistic experiences, either because of danger, inadequacy, or inability to implement them (Alghayth, 2019).

6) Matching individual differences between students: each disability has its own characteristics and educational needs that differ from the rest of the disabilities, where there are varying degrees of impairment for the same disability, for example, there are varying degrees of loss of vision, hearing, or intellectual disability (Alghayth, 2019).

7) Providing opportunities for continuous and self-learning: these individuals, even after obtaining academic qualifications, need to acquire the knowledge and skills imposed by the nature of the changing era and the changing market. By designing training programs based on the use of different educational means, it was possible to help people with disabilities to educate themselves on a continuous basis (Alghayth, 2019).

Polat et al. (2012) conducted research to build an adaptable, web-assisted learning system attributed to the variables of learning disabilities. Data was gathered from five subject area experts (psychologists and special education specialists) using semi-structured interview forms with open-ended questions, 15 parents with at least one kid with a specific learning disability, and six classroom instructors using open-ended survey questions. The study discovered three major findings: a lack of knowledge/interest in particular learning impairments, the insufficiency of the Turkish Ministry of Education's specific learning disabilities support education program, and the inadequacy of applications, both within and outside the classroom. In addition, the findings revealed that students with unique learning difficulties require an adapted web-based solution that can be utilized at school and at home.

Oira (2016) looked at the possibilities of contemporary assistive technologies in improving educational success for pupils with visual impairment, at Kibo's special secondary school. There are 73 boys and 60 girls among the 133 pupils with visual impairments in the target demographic. A total of ten teachers, a transcriber, and a librarian were included in the study. A purposive selection strategy was used to choose a sample of 40 pupils, ten instructors, one librarian, and one transcriber for the study. Questionnaires, an interview schedule, and an observation checklist were used as research tools. According to the study, children with visual impairments in Kenya employ analogous technology such as manual brailers, slate and stylus, abacus, Taylor Frame, cubes, and Cuberithms Board, which are slower, inefficient, and do not correspond to the digital era. The study also discovered that: the use of modern assistive technology has a significant impact on curriculum coverage and early completion of classwork and assignments; assistive technology was in use at Kibos special secondary school in a computer lab where computer lessons were conducted; and assistive technology was in use at Kibos special secondary school in a computer lab where computer lessons were conducted. Computers, Ipads, and tablets were the most often utilized kinds of assistive technology, followed by Braille machines. The most crucial thing to consider when choosing any form of assistive technology was functional eyesight, and the restricted quantity of computers posed the most significant difficulty because sharing machines among the visually handicapped is not advantageous due to sensory loss.

Alghayth (2019) examined the viewpoints of instructors on the usage of assistive technology, assistive technology's efficacy, elements teachers' take into consideration when selecting assistive technology, obstacles, 
and the resources required for effective assistive technology usage with students with severe intellectual and developmental impairments. To collect data from participants, this study employed a self-administered online survey and online interviews. A total of 92 special education instructors were polled from four special education institutes. Five instructors were interviewed in the second phase to offer interpretations for the data evaluated in the first phase. The findings revealed a lack of utilization of assistive technologies, teachers reported using lowtech more than mid-tech or high-tech. Lack of assistive technology equipment, financing, and training were the most commonly mentioned hurdles. The findings also revealed that the four special education institutes, teachers with assistive technology training, and instructors' familiarity with assistive technology all had statistically significant variations in their usage of assistive technology.

Based on the foregoing; The problem of the current research was determined by the low level of students in learning in achievement; And there is a need to employ adaptive media technology to provide interactive media that enrich learning and take into account the educational needs and preferences of students. This problem has been studied by answering the following main question:

- What is the impact of adaptive media technology on developing the achievement of students with learning difficulties in the English language subject?

\section{METHOD AND PROCEDURE}

The current research relied on the quasi-experimental approach to test the validity of the hypotheses, and to verify the effect of adaptive media technology on developing the academic achievement of students with learning disabilities in the English language subject.

\section{Population and Sample Research}

The research population consisted of students with learning difficulties in the Abha region, and the research sample consisted of (38) students from the elementary level in Abha schools in the academic year 2020/2021, they were randomly selected, and all sample members have the basic requirements for dealing with a computer and connecting to a network Internet.

\section{Experimental Design for Research}

The research relied on the quasi-experimental design with one experimental group with pre and post measurement. Figure (1) shows the quasi-experimental design of the research:

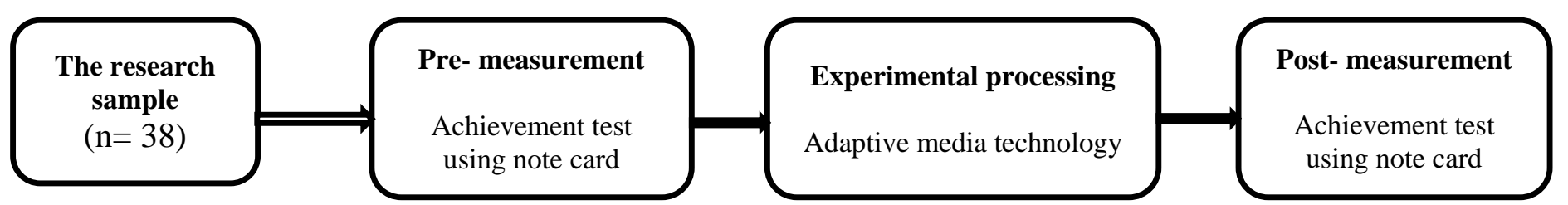

Figure (1): The quasi-experimental design of the research 
To design and develop the adaptive media technology environment, the ADDIE general model for educational design and development was relied upon, as it is a standard model and is characterized by clarity and comprehensiveness for all stages of educational design.

The First Stage: Analysis

At this stage, the characteristics of the students were analyzed, the research problem was analyzed and identified, as well as the identification and analysis of the needs of students with learning disabilities in the skills of using adaptive media technology, as well as the analysis of general objectives, and the identification and analysis of the content of learning skills using adaptive media technology.

The Stage Two: Design

At this stage, the scenario was designed, the behavioral procedural goals were prepared and formulated, and the sources and multimedia were selected and represented, which were texts, images, audios, videos and infographics, in addition to enriching Internet links and PDFs, as well as identifying learning strategies or assessment methods.

The Third Stage: Development

At this stage, the actual implementation of the scenario, the use of authoring software to produce learning resources and media, and the development and production of the environment, according to the following steps:

\section{Design and Production of Learning Resources and Media:}

Where the texts were prepared using the "Microsoft Word" program, the images were prepared using the copy tool, and after assembling the images, they were processed using the "Photoshop" program. The video was also designed and edited using Camtasia Studio, and interfaces and backgrounds were designed with Photoshop.

2. Composing and Producing the Adaptive Media Environment:

The adaptive content was written and produced using the Storyline program, where the main and sub-pages of the content were designed, then the link was activated between all the pages student, and then design a list that includes many enriching sources and diverse media.

The Fourth stage: Implementation

At this stage, the content was packaged according to Scrum standards and then uploaded to the web via the Moodle Learning Management System.

The Fifth Stage: Evaluation

At this stage, the adaptive media technology environment was presented to a group of arbitrators specialized in the field of educational technology, to review the design of the content and make any comments or suggestions, and the environment was also applied to an exploratory sample of (18) students other than the basic research sample, with the aim of monitoring any difficulties or Problems students may encounter.

\section{Research Instruments:}

First: Preparing the achievement test: 
The aim of the test is to measure the achievement of students with learning difficulties of the cognitive aspects of the skills of employing adaptive media technology. To build the test, a specification table was prepared, then the test items was formulated in a multiple-choice type, and the total number of questions was (40), it was prepared electronically, relying on the tools of the learning management system "Moodle", by presenting the test to a group of arbitrators to verify its validity. Some modifications were made, and then the test was verified by calculating the Cronbach's alpha coefficient, and its value was (0.798).

Second: Prepare the note card:

The observation card aimed to measure the performance of students with learning difficulties in the skills of using adaptive media technology. The skills included in the notecard are in the form of phrases describing the expected performance of the students. After that, the notecard was shown to a group of experts, with the aim of expressing their opinions and observations, and in light of this, all the required observations and modifications were made.

\section{Pre-measurement of Research Instruments:}

After the students logged into the learning environment, they were instructed to open and answer the pre-test, and follow them until everyone finished the test, and the note card was pre-applied to all students of the experimental group.

\section{Implementation of Research Experiment and Application of Experimental Processing:}

During the second semester of the academic year 2020/2021, the basic research experiment was started, where students were logged into the learning environment through the Moodle system, then viewed the instructions for use, then directed the students to answer the questionnaires, and then access the displayed content according to for adaptive media technology, all students followed up the presentation and practiced the required skills, then implemented the activities, and students' learning was followed up and communicated with them electronically to answer questions and inquiries and evaluate the activities.

\section{Post- measurement of Research Instruments:}

The post-application of the instruments included re-applying the achievement test and the observation card on the experimental research group, with the aim of measuring the change in behavior as a result of exposure to the experimental treatment.

\section{RESULTS AND DISSCUSION}

The study question has been answered, which states: "What is the effect of adaptive media technology on developing the achievement of students with learning difficulties in English language?" The validity of the first hypothesis was tested, which stated: "There is a statistically significant difference between the mean scores of students with The experimental group in the pre and post applications of the achievement test in favor of the post application, and to verify the validity of this hypothesis, a t-test was used for the related samples, as well as calculating the effect size using the Eta square, and the results were as shown in the following table (1): 
Table (1): Results

\begin{tabular}{cccccccc}
\hline $\begin{array}{c}\text { Achievement Test } \\
\text { Application }\end{array}$ & N & M.S & St.D & T & DF & Sig & $\boldsymbol{\eta}^{\mathbf{2}}$ \\
\hline PRE & 38 & 14.64 & 2.76 & 9.37 & 37 & 0.000 & 0.72 \\
\hline POST & 38 & 24.85 & 6.63 & & & & \\
\hline
\end{tabular}

Table (1) showed that there are statistically significant differences between the mean scores of the experimental group students in the pre and post applications of the achievement test in favor of the post-application, where the calculated " $t$ " value reached (9.37), which is statistically significant, It can also be seen that the value of the 'eta square' $\eta^{2}$ reached $(0.72)$. This indicates the significant impact of adaptive media technology on the development of achievement among students with learning difficulties in the English language subject, and accordingly the research hypothesis is accepted.

It is clear from the previous results that there is an impact of adaptive media technology on improving the achievement of students with learning disabilities, and this is due to the characteristics of adaptive media systems and their capabilities in determining the students' prior knowledge and then matching them with the available information and skills, and then directing each student to the path that suits him according to his experiences and skills needs, as well as learning through adaptive media technology is individually for each student according to his own pace and pace, which helped students to follow up on skills, training on them, and implementing them as well as carrying out the required activities with perfection. Also, The good design of adaptive media, and adjusting its capabilities to take into account students' preferences for multiple media and resources, so that each student chooses the appropriate and preferred media, led to motivating students, continuing learning through preferred media and resources, as well as employing their different senses appropriately during skills training. . Also, providing links and external resources that support skills learning, making the learning environment richer and thus developing students' cognitive and skill aspects. The results of the current research are in agreement with studies of Polat et al. (2012), Oira (2016) and Alghayth (2019).

\section{ACKNOWLEDGEMENTS}

The authors extend their appreciation to the Deanship of Scientific Research at King Khalid University for funding this work through Big Research Groups under grant number (RGP.2 /103/42). References

\section{REFERENCES}

Anindyaputri, N. A., Yuana, R. A., \& Hatta, P. (2020). Enhancing Students' Ability in Learning Process of Programming Language using Adaptive Learning Systems: A Literature Review. Open Engineering, 10(1), 820-829.

Khasawneh, M. A. S. (2021). Attitudes of teachers of learning disabilities in English language towards the use of information technology in Irbid from their point of view. Journal of Advances in Social Science and Humanities, 7(10), 1957-1966.

Paredes, Y. V., \& Hsiao, I. H. (2021). WebPGA: An Educational Technology That Supports Learning by Reviewing Paper-Based Programming Assessments. Information, 12(11), 450.

Oira, M. A. A. G. A. (2016). Use of modern assistive technology and its effects on educational achievement of Students with visual impairment at Kibos special secondary school Kisumu County, Kenya. Unpublished Masters Thesis.

Phobun, P., \& Vicheanpanya, J. (2010). Adaptive intelligent tutoring systems for e-learning systems. Procedia-Social and Behavioral Sciences, 2(2), 4064-4069.

Perelmutter, B., McGregor, K. K., \& Gordon, K. R. (2017). Assistive technology interventions for adolescents and adults with learning disabilities: An evidence-based systematic review and meta-analysis. Computers \& education, 114, 139-163.

Elmabaredy, A., Elkholy, E., \& Tolba, A. A. (2020). Web-based adaptive presentation techniques to enhance learning outcomes in higher education. Research and Practice in Technology Enhanced Learning, 15(1), 1-18. 
Viner, M., Singh, A., \& Shaughnessy, M. F. (2020). Assistive technology to help students with disabilities. Special Education Design and Development Tools for School Rehabilitation Professionals, 240-267.

Khasawneh, M. (2022). The Relationship of Curriculum, Teaching Methods, Assessment Methods, and School and Home Environment with Learning Difficulties in English Language from the Studetns' Perspectives. Journal of Innovation in Educational and Cultural Research, 3(1), 41-48.

Careen, C. (2016). An exploration of teachers' use of assistive technology in inclusive classrooms within the context of universal design for learning and students' response to these methods and tools (Doctoral dissertation, Memorial University of Newfoundland).

Polat, E., Adiguzel, T., \& Akgun, O. E. (2012). Adaptive Web-Assisted Learning System for Students with Specific Learning Disabilities: A Needs Analysis Study. Educational Sciences: Theory and Practice, 12(4), 3243-3258.

Erdem, R. (2017). Students with special educational needs and assistive technologies: A literature review. Turkish Online Journal of Educational Technology-TOJET, 16(1), 128-146.

Standen, P. J., Brown, D. J., Taheri, M., Galvez Trigo, M. J., Boulton, H., Burton, A., ... \& Hortal, E. (2020). An evaluation of an adaptive learning system based on multimodal affect recognition for learners with intellectual disabilities. British Journal of Educational Technology, 51(5), 1748-1765.

\section{AUTHORS}

First Author - Assistant Professor, Special Education Department, King Khalid University, Saudi Arabia.

Second Author -Assistant Professor, Special Education Department, King Khalid University, Saudi Arabia

Correspondence Author - Mohammad Abedrabbu Alkhawaldeh, malkhawaldeh@kku.edu.sa, +966581234183 